\title{
ZPD-2, a Small Compound That Inhibits $\alpha$-Synuclein Amyloid Aggregation and Its Seeded Polymerization
}

\begin{abstract}
Samuel Peña-Díaz',2t, Jordi Pujols 1,2†, María Conde-Giménez ${ }^{3}$, Anita Čarija ${ }^{1,2}$, Esther Dalfo $4,5 \neq$, Jesús García ${ }^{6}$, Susanna Navarro ${ }^{1,2}$, Francisca Pinheiro ${ }^{1,2}$, Jaime Santos ${ }^{1,2}$, Xavier Salvatella, ${ }^{6,7}$, Javier Sancho ${ }^{3}$ and Salvador Ventura ${ }^{1,2,7 *}$

1 Institut de Biotecnologia i Biomedicina, Universitat Autonoma de Barcelona, Barcelona, Spain, ${ }^{2}$ Departament de Bioquimica i Biologia Molecular, Universitat Autonoma de Barcelona, Barcelona, Spain, ${ }^{3}$ Department of Biochemistry and Molecular and Cell Biology, Institute for Biocomputation and Physics of Complex Systems (BIFI), University of Zaragoza, Zaragoza, Spain, ${ }^{4}$ Faculty of Medicine, M2, Universitat Autonoma de Barcelona, Barcelona, Spain, ${ }^{5}$ Faculty of Medicine, University of Vic - Central University of Catalonia, Vic, Spain, ${ }^{6}$ Institute for Research in Biomedicine, The Barcelona Institute of Science and Technology, Barcelona, Spain, ${ }^{7}$ Catalan Institute for Research and Advance Studies, Barcelona, Spain
\end{abstract}

OPEN ACCESS

Edited by:

Sandra Macedo-Ribeiro, University of Porto, Portugal

Reviewed by:

Yoshitaka Nagai,

Osaka University, Japan

Daniel E. Otzen,

Aarhus University, Denmark

${ }^{*}$ Correspondence:

Salvador Ventura

salvador.ventura@uab.es

tThese authors have contributed equally to this work

\#ORCID:

Esther Dalfo

orcid.org/0000-0003-4677-8515

Received: 10 September 2019 Accepted: 28 November 2019

Published: 17 December 2019

Citation:

Peña-Díaz S, Pujols J Conde-Giménez M, Čarija A, Dalfo E, García J, Navarro S, Pinheiro F, Santos J, Salvatella X, Sancho J and

Ventura S (2019) ZPD-2, a Small Compound That Inhibits $\alpha$-Synuclein Amyloid Aggregation and Its Seeded

Polymerization.

Front. Mol. Neurosci. 12:306. doi: 10.3389/fnmol.2019.00306
$\alpha$-Synuclein ( $\alpha$-Syn) forms toxic intracellular protein inclusions and transmissible amyloid structures in Parkinson's disease (PD). Preventing $\alpha$-Syn self-assembly has become one of the most promising approaches in the search for disease-modifying treatments for this neurodegenerative disorder. Here, we describe the capacity of a small molecule (ZPD-2), identified after a high-throughput screening, to inhibit $\alpha$-Syn aggregation. ZPD2 inhibits the aggregation of wild-type $\alpha$-Syn and the A30P and H50Q familial variants in vitro at substoichiometric compound:protein ratios. In addition, the molecule prevents the spreading of $\alpha$-Syn seeds in protein misfolding cyclic amplification assays. ZPD-2 is active against different $\alpha$-Syn strains and blocks their seeded polymerization. Treating with ZPD-2 two different PD Caenorhabditis elegans models that express $\alpha$-Syn either in muscle or in dopaminergic (DA) neurons substantially reduces the number of $\alpha$-Syn inclusions and decreases synuclein-induced DA neurons degeneration. Overall, ZPD2 is a hit compound worth to be explored in order to develop lead molecules for therapeutic intervention in PD.

Keywords: Parkinson's disease, $\alpha$-synuclein, amyloid, protein aggregation, aggregation inhibitor, Caenorhabditis elegans, neurodegeneration

\section{INTRODUCTION}

Parkinson's disease (PD) is a neurodegenerative disorder that affects about $0.3 \%$ of the population and $>1 \%$ of people over 60 years of age (4\% over 80 years) (Nussbaum and Ellis, 2003; Dexter and Jenner, 2013). It is characterized by the loss of dopaminergic (DA) neurons in substantia nigra pars compacta, which compromises the motor capacity of PD-suffering patients, producing tremor, rigidity, and bradykinesia (Marti et al., 2003). Additionally, since the disease spreads to the cerebral cortex (Braak et al., 2003), symptoms could include emotional and cognitive impairment (Marti et al., 2003). Nowadays, treatments are focused on alleviating the above mentioned motor 
symptoms, mostly using dopamine replacement by administration of dopamine precursor (L-DOPA), combined with carbidopa, a L-DOPA decarboxylase inhibitor, and/or catechol-O-methyl transferase inhibitors and monoamine oxidase-B inhibitors (Dexter and Jenner, 2013). However, these treatments do not prevent the progression of PD and they lose efficacy as the disease advances.

Parkinson's disease is pathologically characterized by the accumulation of protein aggregates in the neuronal body, Lewy's bodies (LB), and/or fibrils deposited in neuronal processes, Lewy's neurites (LN), of affected neurons (Spillantini et al., 1997). These inclusions are mainly composed of $\alpha$-synuclein ( $\alpha$-Syn), a protein predominantly expressed in the synaptic termination of DA neurons (Bendor et al., 2013). This evidence, together with the identification of mutations in the gene that encodes for this protein (SNCA) as the cause behind familial cases of PD (Polymeropoulos et al., 1997) and the observation that duplications and triplications of the SNCA gene lead to highly penetrant forms of the disease (Singleton et al., 2003; Ibanez et al., 2004) directly connect PD and $\alpha$-Syn. In fact, the presence of aggregated $\alpha$-Syn in the brain is a common feature of a group of diseases named synucleinopathies, which, in addition to PD, include Dementia with Lewy's bodies (DLB) and multiple system atrophy (MSA), among others (Marti et al., 2003).

In solution, $\alpha$-Syn is a 140 amino acid intrinsically disordered protein whose function seems to be related with vesicle trafficking (Bendor et al., 2013). In vitro it forms thermodynamically stable amyloid aggregates (Serpell et al., 2000) that can display different conformational features ( $\mathrm{Li}$ et al., 2018). The formation of amyloids by $\alpha$-Syn follows the typical sigmoidal kinetics, reflecting a nucleation-polymerization process (Sabate et al., 2003); although secondary nucleation reactions might also occur (Xue et al., 2010). In vivo, $\alpha$-Syn assemblies exert a toxic effect (Winner et al., 2011) and could be transmitted from cell to cell in a prion-like manner by seeding native $\alpha$-Syn aggregation in previously unaffected neurons (Hansen et al., 2011).

Preventing $\alpha$-Syn aggregation seems to hold the potential to achieve significant therapeutic impact. Several strategies have been developed toward this objective: SNCA gene-silencing approaches to decrease the protein levels (McCormack et al., 2010 ), methods to increase the clearance of aggregated $\alpha$-Syn by autophagic and proteasomal machineries (Gao et al., 2019), and molecules intended to avoid the formation and/or propagation of aggregated $\alpha$-Syn (Dehay et al., 2015; Hauser, 2015). One of the main limitations of this last strategy is the absence of a well-defined structure of monomeric $\alpha$-Syn in solution, due to its intrinsically disordered nature, which hampers the rational design of inhibitors. High-throughput screening protocols have been developed to circumvent this problem (Silva et al., 2011; Levin et al., 2014). A number of promising small molecules have been discovered with this approach, including anle138b (Levin et al., 2014), BIOD303 (Moree et al., 2015), fasudil (Tatenhorst et al., 2016), squalamine (Perni et al., 2017), or SynuClean-D (SCD) (Pujols et al., 2018). In this context, we have developed a robust screening and validation protocol to analyze large chemical libraries in the search for effective inhibitors of $\alpha$-Syn aggregation (Pujols et al., 2017). The in vitro pipeline

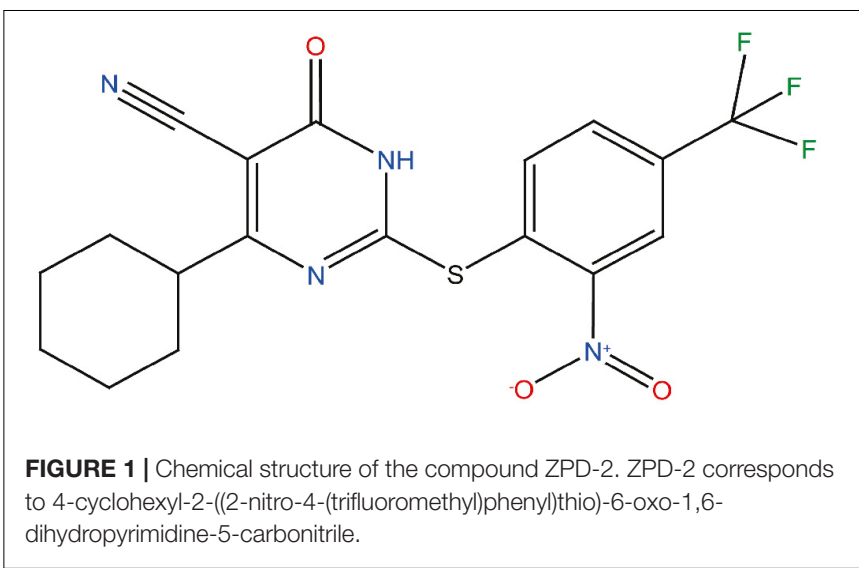

integrates thioflavin-T (Th-T) fluorescence and light scattering measurements, transmission electron microscopy (TEM), and protein misfolding cyclic amplification assays (PMCA). This approach allowed us to identify ZPD-2 (Figure 1) as a novel small molecule able to inhibit the aggregation of wild-type (WT) $\alpha$-Syn, as well as that of the A30P (Kruger et al., 1998) and H50Q (Appel-Cresswell et al., 2013) familial mutants, being active against the seeded polymerization of different $\alpha$-Syn strains. The compound displayed low toxicity for neuronal human cells and demonstrated significant inhibitory capacity in two wellestablished Caenorhabditis elegans models of PD (van Ham et al., 2008; Harrington et al., 2012).

\section{MATERIALS AND METHODS}

\section{Protein Purification}

Protein expression and purification of WT $\alpha$-Syn and its variants (H50Q and A30P) were carried out as previously described (Pujols et al., 2017) and the resulting purified protein was lyophilized and kept at $-80^{\circ} \mathrm{C}$ until its use.

\section{In vitro Aggregation of $\alpha$-Syn}

$\alpha$-Syn was resuspended in sterile PBS and filtered through $0.22 \mu \mathrm{m}$ membranes to remove small aggregates. Aggregation was performed in a sealed 96-well plate, containing $70 \mu \mathrm{M}$ $\alpha$-Syn (WT, A30P or H50Q), $40 \mu \mathrm{M}$ Th-T in PBS $1 \times$, a $1 / 8^{\prime \prime}$ diameter Teflon polyball (Polysciences Europe $\mathrm{GmbH}$, Eppelheim, Germany) and $100 \mu \mathrm{M}$ ZPD-2 or DMSO (in control samples) in a total volume of $150 \mu \mathrm{L}$ per well. The plate was incubated at $100 \mathrm{rpm}$ and $37^{\circ} \mathrm{C}$ after having been fixed in an orbital culture shaker Max-Q 4000 (ThermoScientific, Waltham, MA, United States). Measurements of Th-T fluorescence were done every $2 \mathrm{~h}$ in a Victor3.0 Multilabel Reader (PerkinElmer, Waltham, MA, United States), exciting through a 430-450 nm filter and collecting the emission signal with a 480-510 filter. Each assay was done in triplicate. The values of the aggregation kinetics were fitted to the following Eq. 1 (Crespo et al., 2016):

$$
\propto=1-\frac{1}{k_{\mathrm{b}}\left(e^{k_{\mathrm{a}} t}-1\right)+1}
$$


where $k_{\mathrm{b}}$ and $k_{\mathrm{a}}$ constitute the homogeneous nucleation rate constant and the secondary rate constant (fibril elongation and secondary nucleation), respectively (Crespo et al., 2016).

Titration assays were done by applying different ZPD-2 concentrations $(200,150,100,75,50,25$, and $10 \mu \mathrm{M})$. Timedependent assays were developed by adding $100 \mu \mathrm{M}$ of ZPD-2 at different time points after the beginning of the reaction $(4,8$, $12,16,20$, and $24 \mathrm{~h}$ ). In all cases a fixed concentration of $\alpha$-Syn at $70 \mu \mathrm{M}$ was maintained.

Strains were generated as previously described (Bousset et al., 2013; Peelaerts et al., 2015; Carija et al., 2019). Briefly, lyophilized $\alpha$-Syn was resuspended in PBS $1 \times$ and dialyzed for $24 \mathrm{~h}$ in a

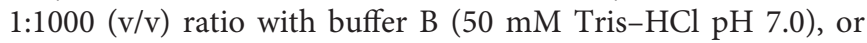
buffer C (50 mM Tris-HCl pH 7.0 supplemented with $150 \mathrm{mM}$ $\mathrm{NaCl})$. Then, the protein was filtered through $0.22 \mu \mathrm{m}$ membrane and incubated at $70 \mu \mathrm{M}$ in presence or absence of $100 \mu \mathrm{M} Z \mathrm{ZPD}$ 2 in a 96-well plate as described above. For the seeding assays, $\alpha$-Syn pre-formed fibrils were sonicated for $5 \mathrm{~min}$ and then added to the aggregation reaction at ratios of $1 \%(\mathrm{v} / \mathrm{v})$ for each condition. The plate was then incubated, and Th-T fluorescence measured as previously indicated.

The soluble fraction was obtained for subsequent quantification by centrifuging $300 \mu \mathrm{L}$ of aggregated sample at $16,900 \times g$ for $90 \mathrm{~min}$. The supernatant was then recovered and loaded into a Tricine-SDS-PAGE gel. Gels were stained with Blue safe. Finally, the density of the $\alpha$-Syn bands was calculated using Quantity One software (Bio-Rad, Hercules, CA, United States). Experiments were done at least in triplicate.

\section{Transmission Electron Microscopy}

End-point $\alpha$-Syn aggregates incubated for $32 \mathrm{~h}$ were collected, diluted 1:10 with PBS $1 \times$ and sonicated for $5 \mathrm{~min}$. Five microliters of these sonicated samples was placed rapidly on a carbon-coated copper grid and incubated for $5 \mathrm{~min}$. The grids were dried with a filter paper to withdraw the excess of sample and immediately washed twice with miliQ water. Finally, $5 \mu \mathrm{L}$ of $2 \%(\mathrm{w} / \mathrm{v})$ uranyl acetate was added to the top of the grid and incubated for $2 \mathrm{~min}$. The excess of uranyl acetate was removed with a filter paper and grids were left to air-dry for $10 \mathrm{~min}$. Images were obtained using a TEM Jeol 1400 (Peabody, MA, United States) operating at an accelerating voltage of $120 \mathrm{kV}$. A minimum of 30 fields were screened per sample, in order to collect representative images.

\section{Light Scattering}

End-point $\alpha$-Syn aggregates were collected, placed into a quartz cuvette, and analyzed in a Cary Eclipse Fluorescence Spectrophotometer (Agilent, Santa Clara, CA, United States). The sample was excited at $300 \mathrm{~nm}$ and the subsequent scattering at $90^{\circ}$ monitored between 280 and $320 \mathrm{~nm}$.

\section{Protein Misfolding Cyclic Amplification}

The PMCA assay was carried out as previously described (Herva et al., 2014). Briefly, $\alpha$-Syn was resuspended to a final concentration of $90 \mu \mathrm{M}$ in Conversion Buffer (PBS $1 \times, 1 \%$ Triton $\mathrm{X}-100,150 \mathrm{mM} \mathrm{NaCl}$ ), supplemented with Complete Protease Inhibitor Mixture (Roche Applied Science, Penzberg, Germany).
Sixty microliters of this $\alpha$-Syn solution was added into $200-\mu \mathrm{L}$ PCR tubes containing $1.0 \mathrm{~mm}$ silica beads (Biospec Products, Bartlesville, OK, United States). Samples were exposed to 24-h cycles of $30 \mathrm{~s}$ sonication and $30 \mathrm{~min}$ incubation at $37^{\circ} \mathrm{C}$, using a Misonix 4000 sonicator, at $70 \%$ power. After every $24 \mathrm{~h}$-cycle, $1 \mu \mathrm{L}$ of the incubated sample was added to a new PCR-tube containing fresh $\alpha$-Syn. This process was repeated for 5 days. In the case of treated samples, ZPD-2 was added in each cycle to the fresh non-sonicated sample to a final concentration of $128 \mu \mathrm{M}$, which corresponds to the $0.7: 1 \alpha$-Syn:ZPD-2 ratio of the previous set of aggregation kinetics assays. Untreated samples were prepared adding the same concentration of DMSO $(0.26 \%)$ present in the treated mixtures. All the reactions were made in triplicate.

At the end of each cycle, $10 \mu \mathrm{L}$ of the incubated samples were diluted 1:10 with $90 \mu \mathrm{L}$ of PBS $1 \times, 40 \mu \mathrm{M}$ Th-T. Th-T fluorescence was measured in a Cary Eclipse Fluorescence Spectrophotometer (Agilent, Santa Clara, CA, United States), exciting at $445 \mathrm{~nm}$ and collecting the emission signal between 460 and $600 \mathrm{~nm}$.

\section{Proteinase K Digestion}

For protein digestion, $6 \mu \mathrm{L}$ of Proteinase $\mathrm{K}(5 \mu \mathrm{g} / \mathrm{mL}$ final concentration) was added to $18 \mu \mathrm{L}$ of PMCA aggregated samples and incubated for $30 \mathrm{~min}$ at $37^{\circ} \mathrm{C}$. After the incubation, $8 \mu \mathrm{L}$ of loading buffer containing $1 \% \beta$-mercaptoethanol was added and the enzyme was thermally inactivated at $95^{\circ} \mathrm{C}$ for $10 \mathrm{~min}$. Finally, $7 \mu \mathrm{L}$ of the incubated and stained samples was loaded into a Tricine-SDS-PAGE gel together with unstained Protein Standard markers (ThermoFisher Scientific, Waltham, MA, United States). Gels were stained with Blue safe.

\section{Nuclear Magnetic Resonance}

Expression of ${ }^{15} \mathrm{~N}$-labeled human WT $\alpha$-Syn was carried out in Escherchia coli BL21 DE3 strain. First, cells were grown in LB medium until an $\mathrm{OD}_{600}$ of 0.6 . The culture was then centrifuged at $3000 \mathrm{rpm}$ for $15 \mathrm{~min}$ and the pellets collected and resuspended in $1 \mathrm{~L}$ minimal medium, composed of: $768 \mathrm{~mL}$ of miliQ water with $1 \mathrm{~mL}$ of ampicillin $100 \mathrm{mg} / \mathrm{mL}, 100 \mu \mathrm{L} \mathrm{CaCl}_{2} 1 \mathrm{M}$, $2 \mathrm{~mL} \mathrm{MgSO}_{4} 2 \mathrm{M}, 20 \mathrm{~mL}$ glucose $20 \%, 10 \mathrm{~mL}$ vitamins $100 \times$ (Sigma-Aldrich, Darmstadt, Germany), $200 \mathrm{~mL}$ salts M9, and $1 \mathrm{~g}^{15} \mathrm{NH}_{4}$ (Cambridge Isotope Laboratories, Inc., Tewksbury, MA, United States). Cells were incubated for $1 \mathrm{~h}$ at $37^{\circ} \mathrm{C}$ and $250 \mathrm{rpm}$. After that, protein expression was induced for $4 \mathrm{~h}$ with $1 \mathrm{mM}$ IPTG. Protein was purified as previously described (Pujols et al., 2017).

${ }^{1} \mathrm{H}_{-}{ }^{15} \mathrm{~N}$ HSQC spectra were obtained at $20^{\circ} \mathrm{C}$ on a Bruker $600 \mathrm{MHz}$ NMR spectrometer equipped with a cryoprobe in a mixture containing $70 \mu \mathrm{M}{ }^{15} \mathrm{~N}$-labeled $\alpha$-Syn, PBS buffer $(\mathrm{pH}$ 7.4), $2.5 \%$ d6-DMSO, and $10 \% \mathrm{D}_{2} \mathrm{O}$ in the absence or in the presence of $100 \mu \mathrm{M} Z \mathrm{ZPD}-2$.

\section{Toxicity Assays}

Neuroblastoma cells were incubated $24 \mathrm{~h}$ in DMEM medium in a 96-well plate before the addition of different concentrations of ZPD-2 (from $1 \mu \mathrm{M}$ to $1 \mathrm{mM}$ ). Cells were incubated for $48 \mathrm{~h}$ at $37^{\circ} \mathrm{C}$ and PrestoBlue ${ }^{\circledR}$ reagent 
(ThermoFisher Scientific, Waltham, MA, United States) was added to analyze cell death. Treated and untreated cells were incubated with PrestoBlue ${ }^{\circledR}$ for $10 \mathrm{~min}$ at $37^{\circ} \mathrm{C}$. Finally, fluorescence emission was measured by exciting at $560 \mathrm{~nm}$ and collecting at $590 \mathrm{~nm}$.

\section{Caenorhabditis elegans Assays Maintenance}

Animals synchronization was carried out by bleaching and overnight hatching in $\mathrm{M} 9\left(3 \mathrm{~g} / \mathrm{L} \mathrm{KH}_{2} \mathrm{PO}_{4}, 6 \mathrm{~g} / \mathrm{L} \mathrm{Na}_{2} \mathrm{HPO}_{4}, 5 \mathrm{~g} / \mathrm{L}\right.$ $\mathrm{NaCl}, 1 \mathrm{M} \mathrm{MgSO}_{4}$ ) buffer. Thus, nematodes were cultured at $20^{\circ} \mathrm{C}$ on growth media plates (NGM) containing $1 \mathrm{mM} \mathrm{CaCl}_{2}$, $1 \mathrm{mM} \mathrm{MgSO} 4,5 \mu \mathrm{g} / \mathrm{mL}$ cholesterol, $250 \mathrm{M} \mathrm{KH}_{2} \mathrm{PO}_{4} \mathrm{pH}$ 6.0, $17 \mathrm{~g} / \mathrm{L}$ Agar, and $3 \mathrm{~g} / \mathrm{L} \mathrm{NaCl}$. Plates were previously seeded with E. coli OP50 strain. Nematodes were maintained using standard protocols (Brenner, 1974).

\section{Strains}

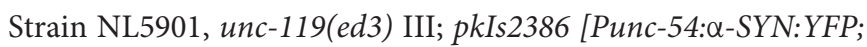
unc-119(+)] was obtained from the C. elegans Genetic Center (CGC). For the $\alpha$-Syn-induced DA degeneration analysis, strain UA196 (Harrington et al., 2012), gifted generously by the laboratory of Dr. Guy Caldwell (Department of Biological Science, The University of Alabama, Tuscaloosa, AL, United States), was used; [sid-1(pk3321); baIn33 (Pdat1:sid-1, Pmyo-2:mCherry); baIn11 (Pdat-1: $\alpha-S Y N ;$ Pdat-1:GFP)]. In the main text, this strain was named Pdat-1:GFP; Pdat1: $\alpha-S Y N$.

\section{ZPD-2 Administration}

After cooled, the autoclaved NGM agar medium (1 $\mathrm{mM} \mathrm{CaCl}_{2}$, $1 \mathrm{mM} \mathrm{MgSO} 4,5 \mu \mathrm{g} / \mathrm{mL}$ cholesterol, $250 \mathrm{M} \mathrm{KH}_{2} \mathrm{PO}_{4} \mathrm{pH}$ 6.0, $17 \mathrm{~g} / \mathrm{L}$ Agar, and $3 \mathrm{~g} / \mathrm{L} \mathrm{NaCl}$ ) was enriched with $100 \mu \mathrm{M}$ of a stock of ZPD-2 in $0.2 \%$ DMSO to a final concentration of $10 \mu \mathrm{M}$. After 2 days, plates were seeded with $250 \mu \mathrm{L}$ of E. coli OP50 with $10 \mu \mathrm{M}$ of ZPD-2. Nematodes were placed on the plates at larval stages L4 and exposed either to ZPD-2 or DMSO (controls) for 7 days. Daily transfer was done to avoid cross progeny.

\section{Aggregate Quantification}

The number of cellular inclusions was quantified as previously described (van Ham et al., 2008; Munoz-Lobato et al., 2014). Briefly, NL5901 (Punc-54: $\alpha-S Y N: Y F P$ ) worms were agesynchronized and left overnight to hatch. Nematodes in phase L1 were cultured and grown into individual NGM plates seeded with E. coli OP50. When animals reached L4 developmental stage, they were transferred onto either ZPD2-treated plates or DMSO-treated plates (negative control). Every day, animals were transferred into a new plate to avoid cross contamination. At stage $\mathrm{L} 4+7$, the aggregates in the anterior part of every single animal were counted. For each experiment, 30 7-day-old nematodes per treatment were analyzed using a Nikon Eclipse E800 epifluorescence microscope equipped with an Endow GFP HYQ filter cube (Chroma Technology Corp., Bellows Falls, VT, United States) and each experiment was carried out in triplicate. Inclusions could be described as discrete bright structures, with edges distinguishable from surrounding fluorescence. ImageJ software was used for measuring the number of cellular aggregates considering the area dimensions. For the quantification of a-syn aggregates in $C$. elegans one single image was taken from each animal. Every image contained among 30-45 stacks $(1 \mu \mathrm{m})$ that allowed to detect aggregates at different animal positions. At least 30 animals were imaged for each assayed condition.

\section{C. elegans Lifespan Analysis}

L4-stage synchronized C. elegans were exposed to $10 \mu \mathrm{M}$ of ZPD2 or DMSO (controls) during lifespan analysis. The worms were classified as alive, dead, or censored every 2 days by determining their movement and response to nose and tail tap. The numbers of alive and dead worms were recorded until all worms perished. The data were plotted as a Kaplan-Meier survival curve and groups compared using a Wilcoxon-test.

\section{C. elegans Neurodegeneration Assays}

Worms were analyzed for $\alpha$-Syn-induced DA neurodegeneration as described previously (Harrington et al., 2012). Briefly, 20-30 L4-staged animals were transferred to ZPD-2 - NGM plates and make them grow up to 7 days (L4 +7 days of development) after which the DA cell death induced by the over-expression of $\alpha$-Syn was analyzed by fluorescence. Plates containing only $0.2 \%$ DMSO, without ZPD-2, were used as control. Worms were transferred daily to avoid cross contamination.

The six anterior DA neurons (four CEP and two ADE DA neurons) were scored for neurodegeneration according to previously described criteria (Sulston et al., 1975; Harrington et al., 2012). Worms were considered normal when all six anterior DA neurons (four CEP, cephalic, and two ADE, anterior deirid) were present without any visible signs of degeneration. If a worm displayed degeneration in at least one of the six neurons, it was scored as exhibiting degeneration. For each independent experiment, 30 worms of each treatment were examined under a Nikon Eclipse E800 epifluorescence microscope equipped with an Endow GFP HYQ filter cube (Chroma Technology Corp., Bellows Falls, VT, United States).

\section{Microscopy and Imaging}

Animals were placed in a $1 \mathrm{mM}$ solution of sodium azide and mounted with a coverslip on a $4 \%$ agarose pad. Animals were visualized with a Nikon Eclipse E800 epifluorescence microscope. The system acquires a series of frames at specific $Z$-axis position (focal plane) using a $Z$-axis motor device. Animals were examined at $100 \times$ magnification to examine $\alpha$-Syn-induced DA cell death and at $40 \times$ to examine $\alpha$-Syn apparent aggregate.

\section{Statistical Analysis}

All graphs were generated with GraphPad Prism 6.0 software (GraphPad Software Inc., La Jolla, CA, United States). Data were analyzed by two-way ANOVA Tukey's HSD test using SPSS software version 20.0 (IBM Analytics, Armonk, NY, United States) and $t$-test using GraphPad software version 6.0 (GraphPad Software Inc., La Jolla, CA, United States). 
All data are shown as means and standard error of mean (SEM). $p<0.05$ was considered statistically significant. In the graphs $*$, **, and $* * *$ indicate $p<0.05, p<0.01$, and $p<0.001$, respectively.

\section{RESULTS}

\section{ZPD-2 Reduces and Delays the Aggregation of Human $\alpha$-Synuclein in vitro}

We designed and optimized a screening protocol that allows to follow the aggregation kinetics of $\alpha$-Syn by monitoring Th$\mathrm{T}$ fluorescence emission for $32 \mathrm{~h}$. This approach permitted us to study the inhibitory potential of more than 14,000 compounds (Pujols et al., 2017, 2018). The activity of molecules able to reduce significantly the final amount of Th-positive material and/or impact the nucleation or elongation rates of the reaction was further confirmed using light scattering and TEM measurements at the end of the reaction. This allowed us to identify 30 active compounds, most of which seem not to be connected in terms of structure, precluding QSAR studies. We have previously described the properties of SCD a molecule that acts preferentially on top of $\alpha$-Syn proto-fibrillar or fibrillar assemblies (Pujols et al., 2018). Here, we describe the properties of ZPD-2 (Figure 1), a compound that differs in its mechanism of action. SCD and ZPD-2 share a benzotrifluoride group, which suggested that it could constitute the minimal inhibitory unit; however, this group is devoid of any anti-aggregation activity by itself (unpublished), indicating that, most likely, it only acts as a framework for the different active groups in the two molecules.

The incubation of $70 \mu \mathrm{M}$ of $\alpha$-Syn in the presence and absence of $100 \mu \mathrm{M}$ of $\mathrm{ZPD}-2$ revealed that the compound modulated the protein aggregation, reducing the formation of Th- $\mathrm{T}$ positive structures at the end of the reaction by an $80 \%$, while extending $t_{50}$ by $8 \mathrm{~h}$ (Figure $2 \mathrm{~A}$ ). The analysis of the kinetics revealed a reduction in the nucleation rate constant in presence of ZPD-2 $\left(k_{b}=0.008833\right)$ by threefold, when compared to the control reaction $\left(k_{\mathrm{b}}=0.02754\right)$. The autocatalytic rate constant was also lower in the treated sample $\left(k_{\mathrm{a}}=0.2432 \mathrm{~h}^{-1}\right)$ than in the control $\left(k_{\mathrm{a}}=0.3230 \mathrm{~h}^{-1}\right)$. Light scattering measurements at $300 \mathrm{~nm}$ confirmed that the observed reduction in $\mathrm{Th}-\mathrm{T}$ fluorescence corresponds to an effective decrease in the levels of $\alpha$-Syn aggregates, with a $67 \%$ decrease in the dispersion of light in the presence of ZPD-2 (Figure 2B). TEM images corroborated that the samples incubated with ZPD2 (Figure 2D) contained less fibrils per field than the nontreated ones (Figure 2C). In good agreement with these data, quantification of soluble $\alpha$-Syn at the end of the aggregation reaction indicated that its level was threefold higher in ZPD-2treated samples (Supplementary Figure S1A).

Further analysis of the inhibition capacity of ZPD-2 indicated that it exhibited a dose-dependent effect, displaying a statistically significant effect even at $10 \mu \mathrm{M}$ (1:7 compound:protein ratio) (Figure 3A), where the final Th-T signal was reduced by $49 \%$.
To address the time window in which ZPD-2 is active, we set up aggregation reactions with a constant amount of ZPD-2 added at different time points after the reaction begins. A time-dependent response was observed (Figure 3B), with a very significant inhibition when ZPD-2 was added at early $(4-8 \mathrm{~h})$ and intermediate $(12-16 \mathrm{~h})$ times, and a less pronounced effect when it was added at the plateau phase $(20-24 \mathrm{~h})$. This indicates that ZPD-2 is mostly active against the species formed early in the aggregation reaction, consistent with its highest impact on the nucleation rate constant $k_{\mathrm{b}}$. Importantly, NMR studies using isotopically labeled monomeric and soluble $\alpha$-Syn indicated that ZPD-2 does not interact with its native form, since we could not detect any perturbations in chemical shifts or peak intensities in $\alpha$-Syn in the presence of a molar excess of the molecule (Supplementary Figure S2).

Several $\alpha$-Syn single point mutations are connected with the onset of familial cases of PD (Kruger et al., 1998; AppelCresswell et al., 2013). We studied the ability of ZPD-2 to prevent the aggregation of two of the most frequent and aggressive variants, $\mathrm{H} 50 \mathrm{Q}$ and $\mathrm{A} 30 \mathrm{P}$. The molecule was also active against these $\alpha$-Syn forms in kinetic assays (Figure 4A). According to the relative Th- $\mathrm{T}$ signal at the end of the reaction in $\mathrm{ZPD}$-2-treated and non-treated samples, the molecule inhibited the aggregation of A30P and H50Q by 96 and $94 \%$, respectively (Figure $4 B$ ).

\section{ZPD-2 Prevents $\alpha$-Syn Seeded Aggregation in Protein Misfolding Cyclic Amplification Assays}

Protein misfolding cyclic amplification assays, initially developed to study the polymerization and propagation process of the prion protein (Barria et al., 2012; Morales et al., 2012), has been recently adapted for $\alpha$-Syn amyloid aggregation (Herva et al., 2014). Essentially, cycles of incubation at $37^{\circ} \mathrm{C}$ are followed by vigorous sonication in order to allow fibril growth and subsequent fibrillar rupture, thus producing $\alpha$-Syn seeds. These preformed seeds are used to trigger the aggregation of fresh protein in the following cycle, amplifying the fibrillar content. At $90 \mu \mathrm{M}$ of $\alpha$-Syn, PMCA produced amyloid structures resistant to protease $\mathrm{K}(\mathrm{PK})$ digestion, as observed by SDS-PAGE, with the maximum protection arising after four rounds (Figure 5A, middle). Th$\mathrm{T}$ fluorescence measurements of the same samples indicated that this protection correlates with an increasing presence of amyloid-like assemblies (Figure 5B). In sharp contrast, in the presence of ZPD-2, the amount of PK-resistant protein after four rounds is negligible (Figure 5A, right), Th-T fluorescence signal being also significantly low relative to control samples at this stage (Figure 5B). These results suggested that ZPD-2 was strongly interfering with the PMCApromoted seeding of $\alpha$-Syn amyloids. The fact that Th-T decrease becomes significant only at pass 4, likely indicates that the aggregated non PK-resistant species generated at early steps still retain certain Th-T binding ability, since SDS-PAGE analysis indicates that the levels of PK-resistant 


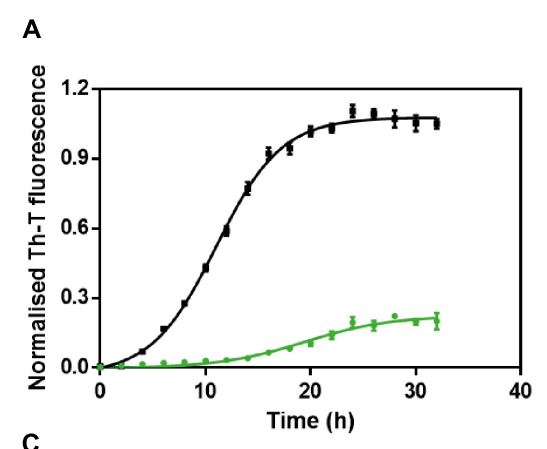

B
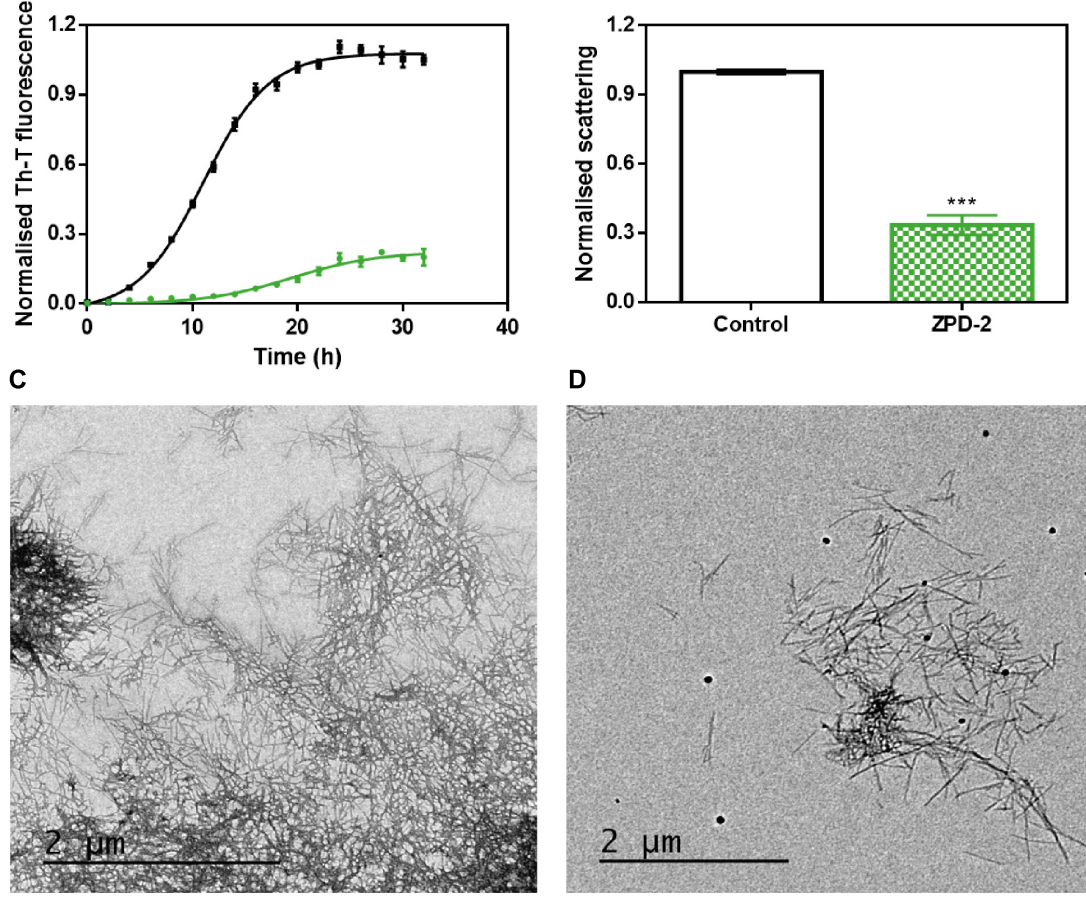

D

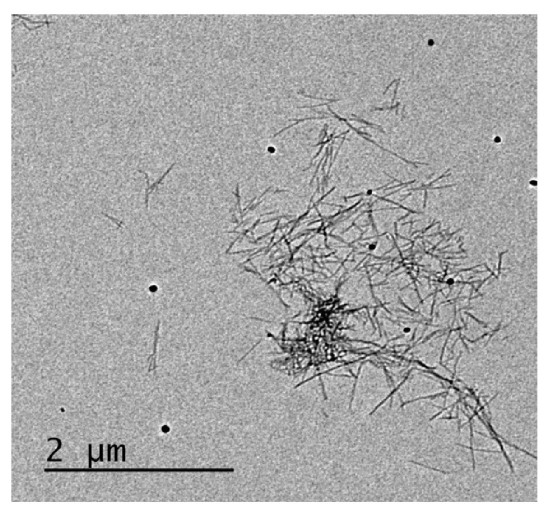

FIGURE 2 | ZPD-2 inhibits the aggregation of wild-type $\alpha$-synuclein in vitro. (A) Aggregation kinetics of $\alpha$-Syn in absence (black) and presence (green) of ZPD-2. Intensity of Th-T fluorescence is plotted as a function of time. (B) Light scattering of end-point aggregates is measured at $300 \mathrm{~nm}$ for untreated (white) and ZPD-2-treated samples (green). (C,D) Representative TEM images of untreated (C) and ZPD-2-treated (D) samples. Th-T fluorescence is expressed as normalized means. Final points were obtained at $48 \mathrm{~h}$ after the aggregation reaction begin. Error bars are shown as standard errors of mean values, ${ }^{* * *} p<0.001$.
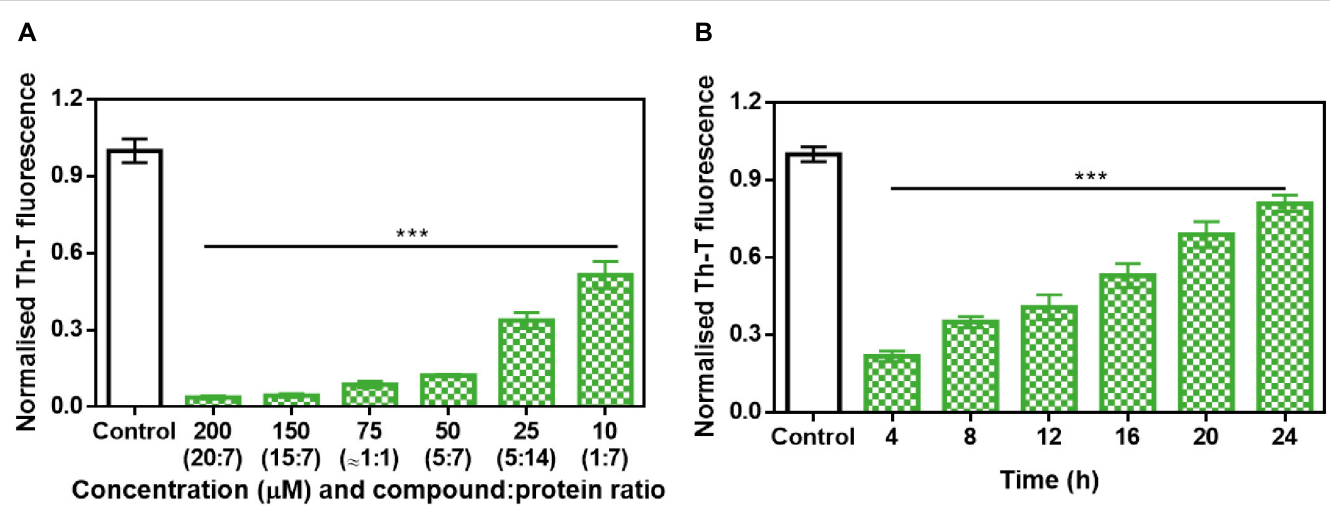

FIGURE 3 | Analysis of the inhibitory capacity of ZPD-2. (A) Titration of the effect of different concentrations of ZPD-2 on $70 \mu \mathrm{M} \alpha$-Syn aggregation. (B) Th-T fluorescence of $\alpha$-Syn end-point aggregates after the addition of ZPD-2 at different time points during the aggregation kinetics. Th-T fluorescence is plotted as normalized means. End-points were obtained at $48 \mathrm{~h}$ of $\alpha$-Syn incubation. Error bars are shown as standard errors of mean values, ${ }^{* * *} p<0.001$.

protein is already decreased in treated samples at passes $1-3$ (Supplementary Figure S3).

\section{ZPD-2 Prevents the Aggregation of Different $\alpha$-Synuclein Amyloid Conformations}

The aggregation of $\alpha$-Syn has been described to lead to the formation of different amyloid conformations, or strains, depending on the environmental conditions ( $\mathrm{Li}$ et al., 2018); a property that has been linked with its spreading in the brain and the manifestation of different synucleinopathies (Peelaerts et al., 2015). We analyzed the capacity of ZPD-2 to prevent the aggregation of $\alpha$-Syn into different previously described amyloid conformations (Bousset et al., 2013; Carija et al., 2019). We refer them as strain $\mathrm{B}$ (buffer $\mathrm{B}, 50 \mathrm{mM}$ Tris- $\mathrm{HCl} \mathrm{pH}$ 7.0) and strain $\mathrm{C}$ (buffer C, 50 mM Tris- $\mathrm{HCl}$ pH 7.0 supplemented with $150 \mathrm{mM}$ $\mathrm{NaCl}$ ), to keep the original strain nomenclature. ZPD-2 was 
A

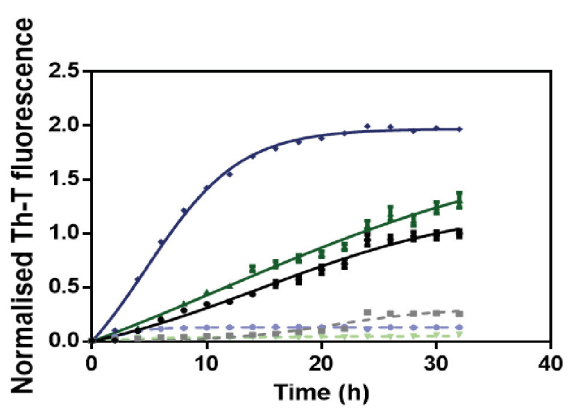

B

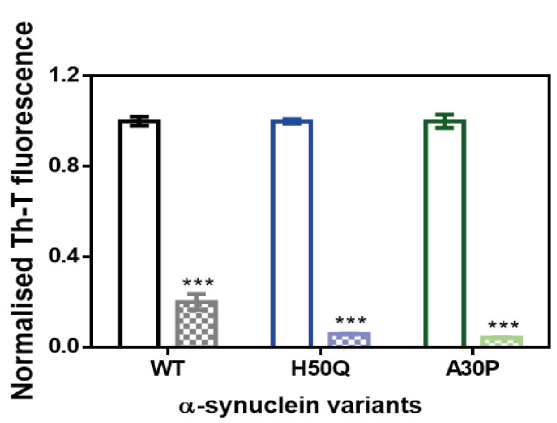

FIGURE 4 | ZPD-2 inhibits the aggregation of $\alpha$-synuclein familial variants. (A) Aggregation kinetics of WT (black), H50Q (blue), and A30P (green) variants of $\alpha$-Syn in presence (dotted) and absence (continuous) of ZPD-2, using Th-T as reporter. (B) End-point measurements of the aggregation of WT, H50Q, and A30P variants of $\alpha$-Syn in presence (dotted) or absence (continuous) of ZPD-2 Th-T fluorescence are expressed as normalized means. Error bars are shown as standard errors of mean values.

A

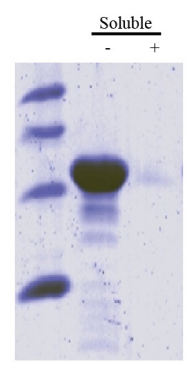

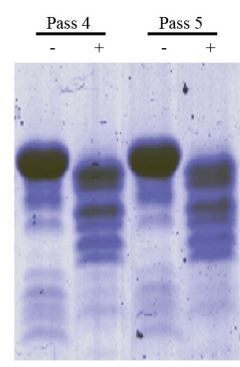

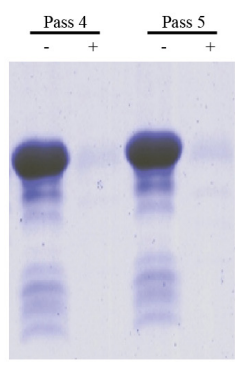

B

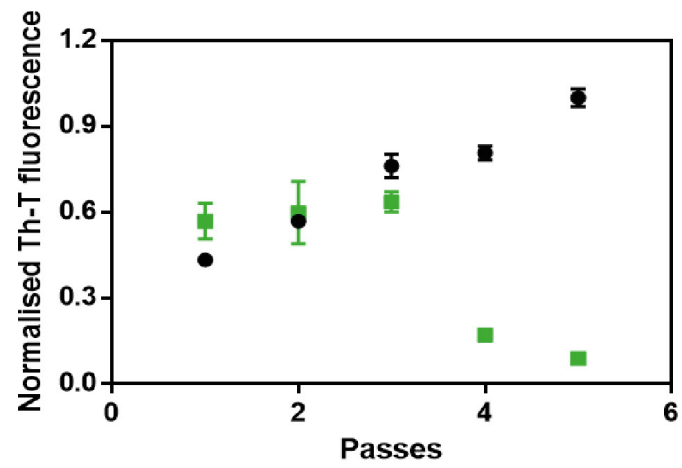

FIGURE 5 | PMCA of $\alpha$-synuclein in presence of ZPD-2. (A) Tricine-SDS-PAGE gels of untreated (middle) and ZPD-2-treated (right) PMCA samples before (-) and after (+) being digested with proteinase K. (B) Th-T fluorescence of different PMCA cycles of treated (green) and untreated (black) samples. Soluble $\alpha$-Syn and PMCA steps 4 and 5 are shown. Th-T fluorescence is plotted as normalized means. Error bars are shown as standard errors of mean values.

active in both cases (Figures 6A,E), inhibiting by up to $90 \%$ the formation of the amyloid strains $\mathrm{B}$ and $\mathrm{C}$, as monitored by Th$\mathrm{T}$ fluorescence. Light scattering measurements (Figures 6B,F) and TEM imaging (Figures $\mathbf{6 C}, \mathbf{D}, \mathbf{G}, \mathbf{H}$ ) and soluble protein quantification at the end of the reaction (Supplementary Figure S1B) of the different samples confirmed the inhibitory activity of ZPD-2 against the two strains. Non-fibrillar aggregates might be necessary for fibril formation (obligate), able to convert into fibrils, but not indispensable for fibril formation (on-pathway), or unable of converting directly to fibrils (off-pathway). The difference between the large reduction in Th- $\mathrm{T}$ fluorescence promoted by ZPD-2 in strain $\mathrm{C}$ aggregation kinetics and the moderate impact the molecule has in light scattering and soluble protein levels might indicate the formation of Th- T negative offpathway aggregates in these conditions, since they do not evolve into fibrils. However, their size should be rather small, since we did not observe any large amorphous aggregate in ZPD-2-treated samples (Figure 6H).

We addressed whether the strong inhibitory capability of ZPD-2 at neutral $\mathrm{pH}$ can be overridden by the presence of preformed fibrils able to seed the aggregation reaction. The addition of $1 \%(\mathrm{v} / \mathrm{v})$ of seeds effectively accelerated the formation of both $\mathrm{B}$ and $\mathrm{C}$ strains (Figures 7A,B). However, the presence of ZPD-2 abrogates this effect, reducing the final amount of amyloid-like structures in seeded reactions by an $87 \%$ for strain B (Figure 7A) and a 90\% for strain C (Figure 7B), according to Th-T fluorescence. Again, light dispersion measured at $300 \mathrm{~nm}$ revealed a significant decrease of aggregates by 57 and $70 \%$ in the case of strains B and C, respectively (Figures 7C,D).

\section{ZPD-2 Reduces the Formation of $\alpha$-Synuclein Inclusions in a C. elegans Model of PD}

We assessed the toxicity of ZPD-2 for human neuroblastoma cells. No significant toxicity was observed when the molecule was added to the cell culture up to $80 \mu \mathrm{M}$ (Supplementary Figure S4). We skipped efficacy studies on neuroblastoma cells, because, with more than 20 different compounds analyzed, we could not find a straightforward connection between the potency of the molecules in cell cultures and that in our C. elegans models of PD. We first analyzed the effect of ZPD-2 in the C. elegans 


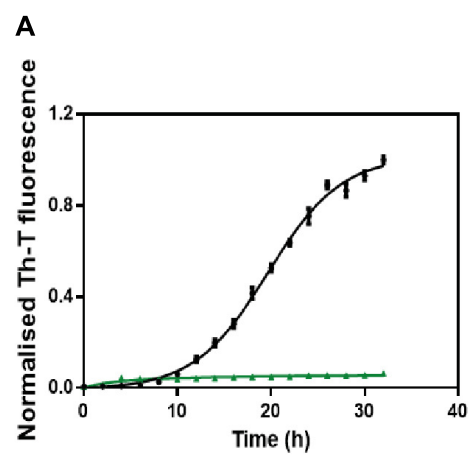

E

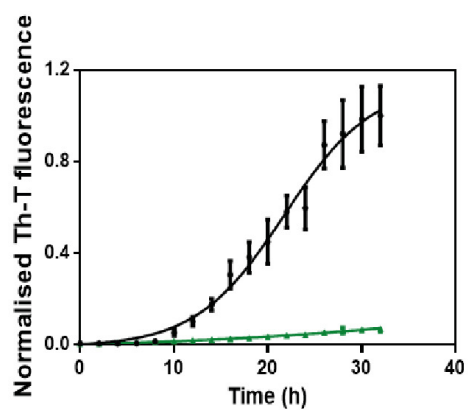

B

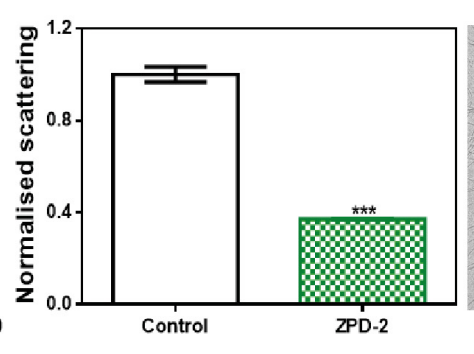

F

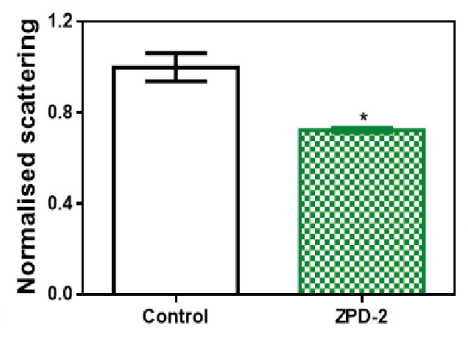

C

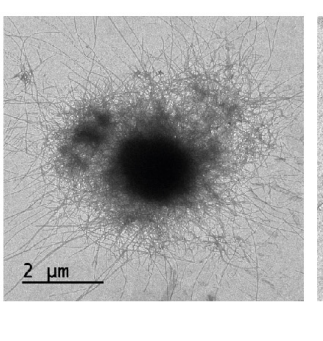

$\mathbf{G}$

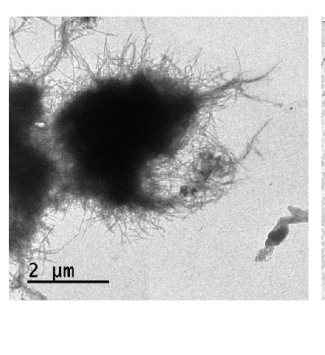

D

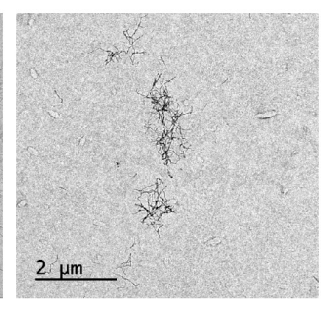

H

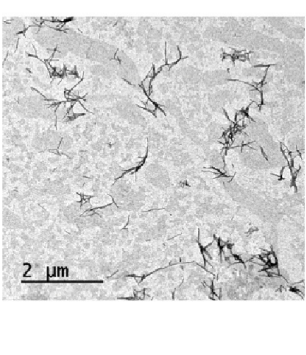

FIGURE 6 | ZPD-2 blocks the aggregation of two different $\alpha$-synuclein strains. (A,E) Aggregation kinetics of $\alpha$-Syn strains B (A) and C (E) in absence (black) and presence (green) of ZPD-2. (B,F) Light scattering final point measurements at $300 \mathrm{~nm}$ of untreated (white) and ZPD-2-treated samples (green) of strains B (B) and C (F). (C,D,G,H) Representative TEM images of untreated $\alpha$-Syn aggregates $\mathbf{( C , G )}$ and treated $\mathbf{( D , H )}$ samples for strains B and C, respectively. Th-T fluorescence is expressed as normalized means. Final points were obtained at $48 \mathrm{~h}$ after the aggregation reaction begins. Error bars are shown as standard errors of mean values, where $p<0.05$ and $p<0.001$ were indicated by * and ***, respectively.

strain NL5901. This strain over-expresses human $\alpha$-Syn fused to the yellow fluorescent protein (YFP), under the control of the muscular unc-54 promoter, transgene phIs2386 (Punc-54: $\alpha$ $S Y N: Y F P)$. The expression of human $\alpha$-Syn in the muscle of this nematode has been successfully used to identify modifier genes (Hamamichi et al., 2008; van Ham et al., 2008). Animals at the fourth larval stage (L4) were incubated in the presence or absence of $10 \mu \mathrm{M}$ ZPD-2 and analyzed at 9 days post-hatching $(\mathrm{L} 4+7)$. These aged worms, which mimic aged PD patients, were then analyzed by epifluorescent microscopy and the number of visible $\alpha$-Syn inclusions was quantified (Figures $\mathbf{8 A , B}$ ). In these assays, ZPD-2 moderately, but significantly, reduced the number of apparent aggregates $(25.7 \pm 1.3)$ when compared to untreated worms (31.8 \pm 1.7 ) (Figure $8 \mathrm{C}$ ). In addition, worms treated with ZPD-2 showed an increase in their mean lifespan of $14.2 \%$, relative to untreated animals ( $p$-value $=0.015$, Wilcoxon unpaired test) (Supplementary Figure S5).

\section{Neuroprotective Role of ZPD-2 in a C. elegans Model of PD}

The loss of DA neurons is one of the most important characteristics of PD and an important target in the search for a future treatment for this disorder. C. elegans presents a total of four pairs of DA neurons, three of them in the anterior part (CEPD, CEPV, and ADE) and one pair in the posterior part (PDE)
(Sulston et al., 1975). The existence of six anterior DA neurons has been recently used to analyze PD-related processes in a model (strain UA196) that expresses both human $\alpha$-Syn and GFP under the control of the dopamine transporter promoter (Pdat-1:GFP; Pdat-1: $\alpha-S Y N)$ (Kim et al., 2018). Human $\alpha$-Syn expression in these DA neurons induces a progressive degeneration process (Cao et al., 2005). At 9 days post-hatching, the number of remaining functional neurons of untreated (Figure 9A) and ZPD-2-treated (Figure 9B) worms was analyzed. As an average, in control worms $48.1 \%$ of DA neurons are non-functional, whereas in treated animals this value decreases to $40.4 \%$ ( $p$ value $=0.038$, Wilcoxon unpaired test). Despite the difference between both means is rather low, the distribution of the data indicated a displacement in the DA neurons survival profile (Figure 9C and Supplementary Figure S6) in the presence of ZPD-2 when compared to the control worms. As a result, there is a significant increase in the number of worms containing more than three functional neurons in the anterior region in the presence of ZPD-2 $(51.0 \pm 4.8 \%)$ when compared to the controls $(29.1 \pm 3.1 \%)$ (Figure 9D).

\section{DISCUSSION}

Protein aggregation is tightly connected with neurodegenerative disorders such as Alzheimer's and PDs. Immediately after the 


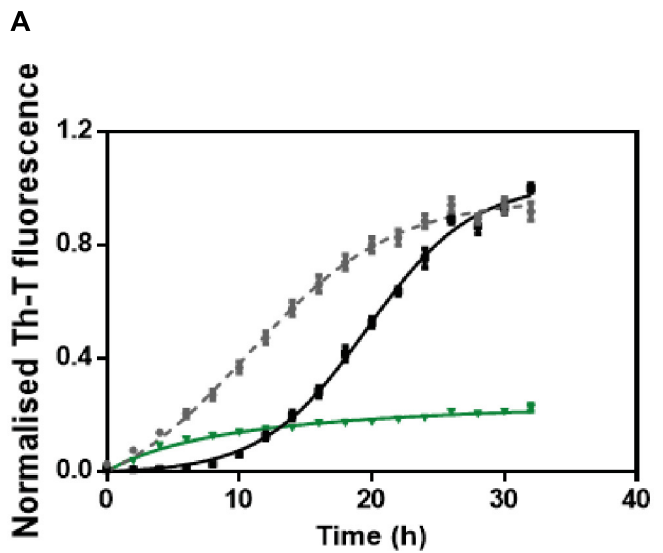

C

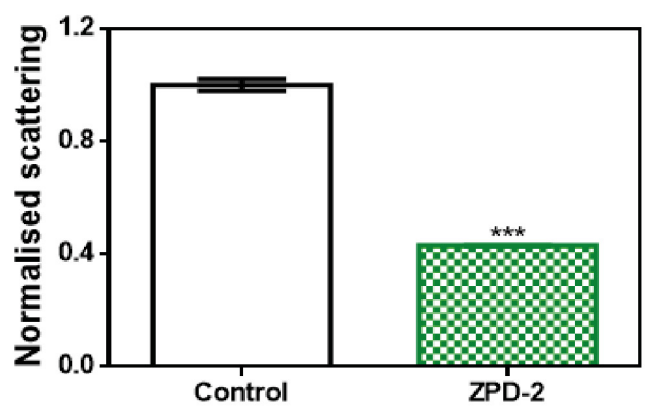

B

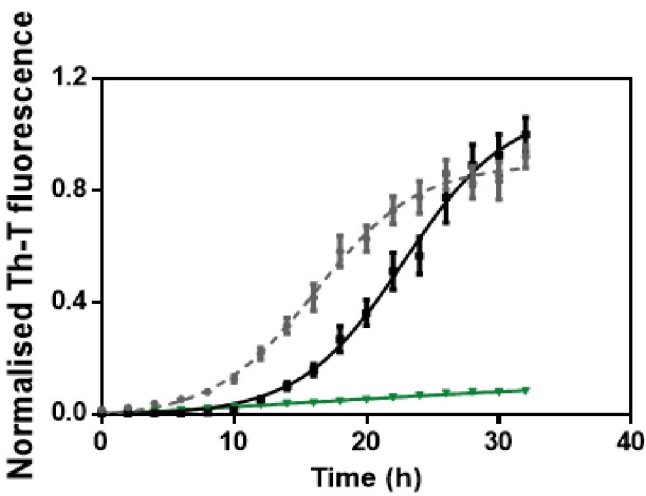

D

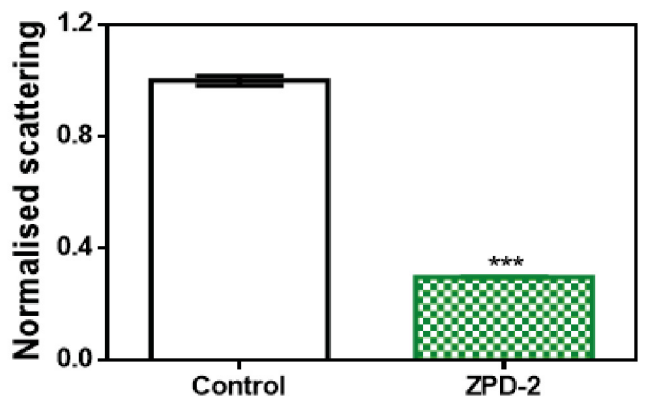

FIGURE 7 | Seeding assays with three different strains. (A,B) Aggregation kinetics of $\alpha$-Syn, buffer B (50 mM Tris- $\mathrm{HCl}$ pH 7.0$)$ (A), or buffer C (50 mM Tris-HCl pH 7.0 supplemented with $150 \mathrm{mM} \mathrm{NaCl}$ (B), reported by Th-T fluorescence, in absence of compounds and seeds (black), in presence of $1 \%$ ( $\mathrm{v} / \mathrm{V}$ ) of preformed seeds at the specific condition (gray dotted line) and in presence of seeds and $100 \mu \mathrm{M}$ of ZPD-2 (green). Light dispersion of treated (green) and untreated (white) seeded samples at final point of strain B (C) and strain C (D). Error bars are shown as standard errors of mean values, ${ }^{* * *} p<0.001$.

A

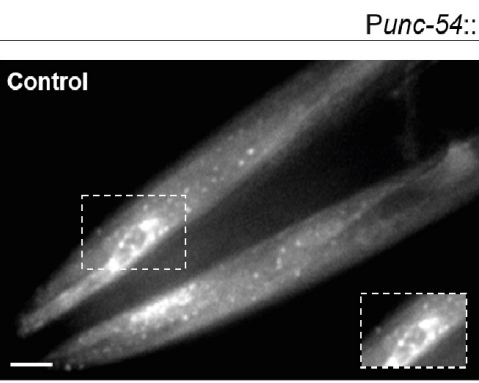

B

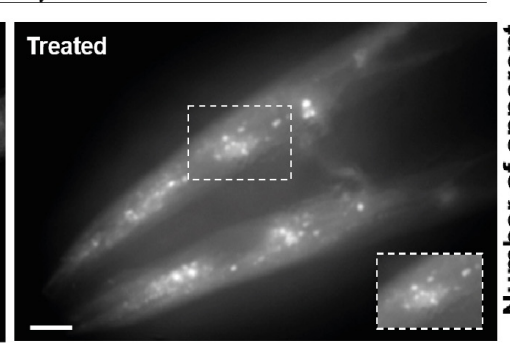

C

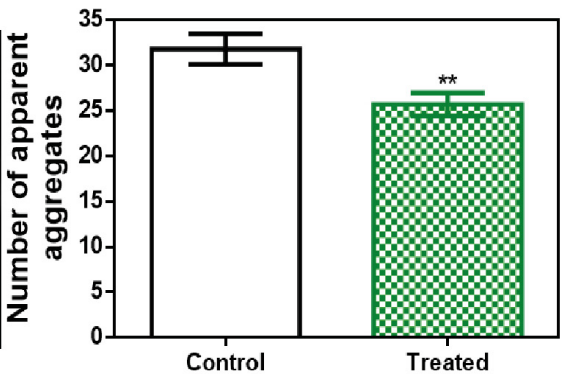

FIGURE 8 | In vivo anti-aggregational assays in Caenorhabditis elegans. Representative images of apparent $\alpha$-Syn aggregates in C. elegans body wall muscle cells obtained by epifluorescence microscopy of NL5901 worms treated without (A) and with ZPD-2 (B). (C) Quantification of $\alpha$-Syn muscle inclusions in the absence (white) and presence of ZPD-2 (green). ${ }^{* *} p<0.01$.

identification of $\alpha$-Syn as the main fibrillar component in LBs and LNs (Spillantini et al., 1997, 1998) it became evident that targeting the aggregation of this protein might hold therapeutic potential (Tatenhorst et al., 2016).

Nevertheless, the absence of a defined three-dimensional structure for the functional state of $\alpha$-Syn due to its intrinsically disordered nature makes the rational design of effective inhibitors that stabilize $\alpha$-Syn and thus prevent or delay its aggregation, as it has been successfully done for globular proteins like transthyretin (Bulawa et al., 2012; Sant'Anna et al., 2016), difficult. In this scenario, evaluation of large chemical libraries appears as one of the few strategies we have to discover an effective inhibitor of $\alpha$-Syn deposition and, indeed, this approach has already rendered promising molecules (Levin et al., 2014; Moree et al., 2015; 
A

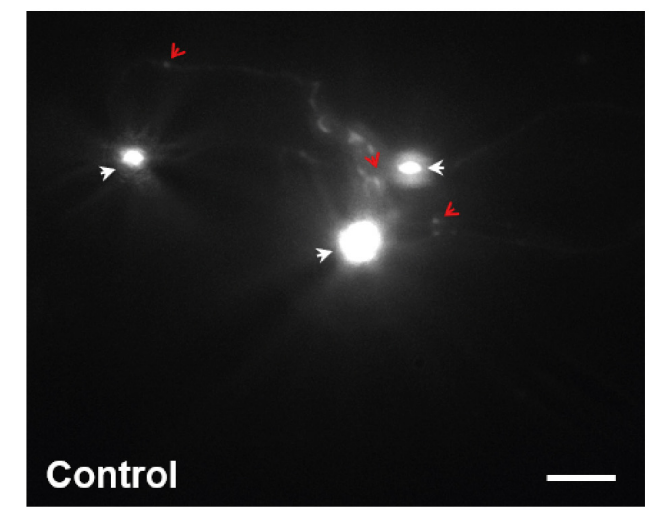

C

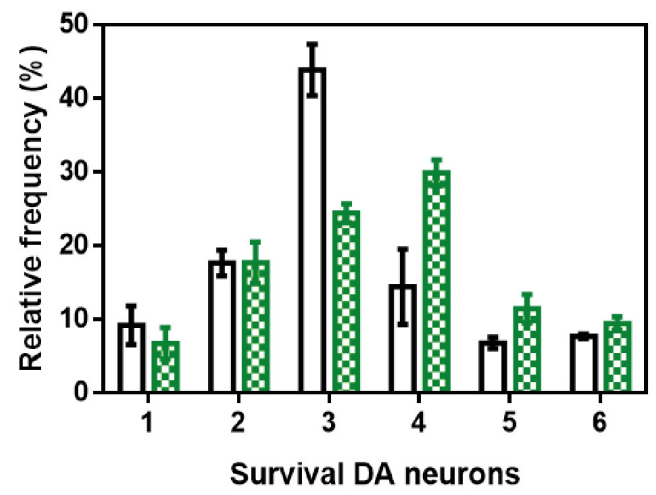

B

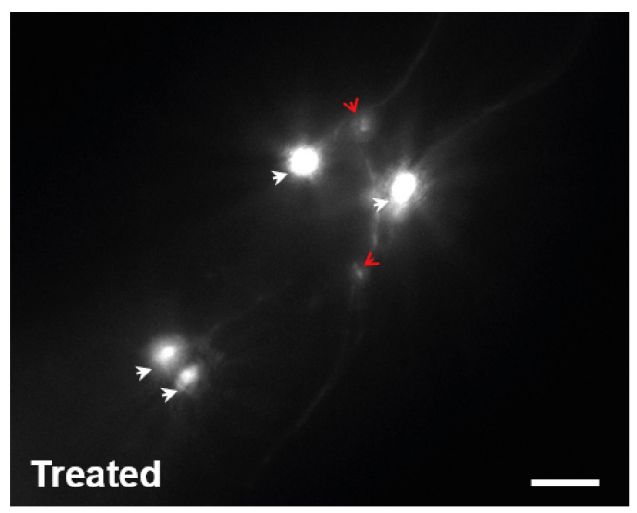

D

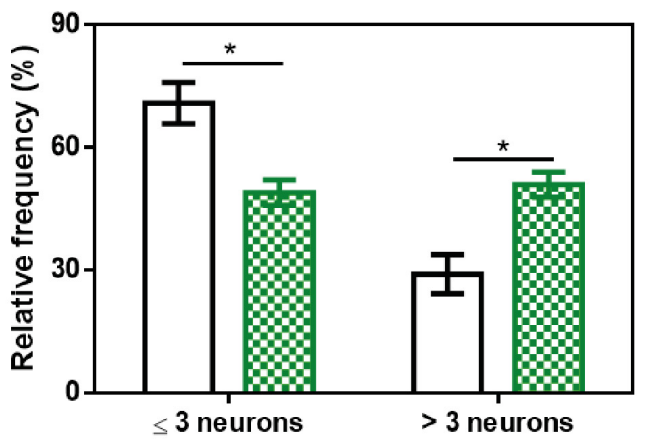

FIGURE 9 | Neuroprotective activity of ZPD-2 in a Caenorhabditis elegans model of PD. Representative images of GFP and $\alpha$-Syn expressing anterior DA neurons in worms treated without (A) and with ZPD-2 (B) for 7 days after L4. Healthy neurons are labeled with white arrows. (C) Distribution of DA surviving neurons in the anterior region of worms. (D) Percentage of worms containing three neurons functional or less and more than three functional neurons after 7 days post-hatching. White bars indicate control samples while the green ones correspond to treated samples. ${ }^{*} p<0.05$.

Tatenhorst et al., 2016; Perni et al., 2017; Pujols et al., 2018). In the present work, we describe the discovery of ZPD-2, a small molecule able to prevent up to $90 \%$ the in vitro aggregation of WT $\alpha$-Syn and of familial mutants of the protein when used in a $0.7: 1$ (protein:ZPD-2) ratio, delaying also significantly the completion of the reaction. Its inhibitory capacity was confirmed by orthogonal techniques such as light scattering and TEM.

Further analysis demonstrated that ZPD-2 was able to prevent the aggregation in a concentration-dependent manner, with $\sim 50 \%$ inhibition at a 7:1 protein:compound ratio. This, together with solution NMR measurements indicate that ZPD-2 does not interact significantly with soluble monomeric $\alpha$-Syn, which suggests that it will not interfere with the functional state of the protein. In addition, the inhibitory potential of ZPD is time-dependent, being more significant at early $(0-8 \mathrm{~h})$ stages, in fair contrast with SC-D, a compound we identified in the same screening campaign, whose activity was time-independent, being able to target late species (Pujols et al., 2018). The largest affinity of ZPD-2 for early aggregating species is also inferred from the fact that it mainly impacts the nucleation constant, reducing it by threefold. This might also explain why, at a 0.7:1 ratio, the molecule works well for the A30P (96\% inhibition) and H50Q (94\% inhibition) familial variants, provided that both mutations facilitate oligomerization, H50Q favoring also fibrillation (Marvian et al., 2019).

ZPD-2 is able to inhibit the aggregation of $\alpha$-Syn under different solution conditions. This ability opens a possibility for its use in different synucleinopathies, where different $\alpha$-Syn strains might occur (Bousset et al., 2013; Peelaerts et al., 2015). Importantly, ZPD-2 is one of a few small molecules shown to inhibit efficiently $\alpha$-Syn seeded aggregation, where the lag phase of the reaction is shortened or abrogated because the soluble protein can be directly incorporated on top of the preformed fibrillar fragments. This seeding-blocking activity explains why ZPD-2 is so effective preventing the formation of PK-resistant/Th-T-positive species in PMCA assays, which promote both templated seeding and aggregates amplification. This effect might respond to the ability of the compound to either destabilize small aggregates or to prevent their elongation, a property that can be very relevant to prevent the cell-to-cell spreading of misfolded $\alpha$-Syn.

ZPD-2 had not detectable toxic effect for neuronal cells at $10 \mu \mathrm{M}$, a concentration at which it reduces the presence of $\alpha$-Syn inclusions in a C. elegans model of PD expressing human $\alpha$-Syn 
in body wall muscle cells and extends lifespan. Not surprisingly, this anti-aggregational activity translates in reduced DA neurons degeneration in a $C$. elegans model that over-expresses human $\alpha$-Syn exclusively in these cells, increasing significantly the proportion of animals that keep $>50 \%$ of their anterior part DA neurons intact.

\section{CONCLUSION}

In conclusion, $\mathrm{ZPD}-2$ properties make this molecule a promising hit for the sake of developing leads able to tackle $\alpha$-Syn aggregation and seeds propagation in PD and, potentially, other synucleinopathies.

\section{DATA AVAILABILITY STATEMENT}

All datasets generated for this study are included in the article/Supplementary Material.

\section{AUTHOR CONTRIBUTIONS}

SP-D, JP, XS, JavS, ED, and SV conceived and designed the experiments, and analyzed the results. SP-D, JP, FP, JaiS, and MC-G performed the aggregation assays. AC expressed and purified the H50Q and A30P variants. SP-D and SN performed the PMCA assays. SN performed the toxicity assays. JG and XS performed the NMR assays. SP-D and ED performed the C. elegans tests. SP-D, JP, and SV wrote the manuscript.

\section{FUNDING}

SV was supported by the Ministerio de Economía y Competitividad (MINECO) (BIO2016-78310-R), the ICREA (ICREA-Academia 2015) and the Fundación La Marató de TV3 (Ref. 20144330). JavS was supported by the MINECO (BFU2016-78232-P) and the Gobierno de Aragón (E45_17R). ED was supported by the Instituto de Salud Carlos III (PH613883/ERDF/ESF). JG and XS were supported by the

\section{REFERENCES}

Appel-Cresswell, S., Vilarino-Guell, C., Encarnacion, M., Sherman, H., Yu, I., Shah, B., et al. (2013). Alpha-synuclein p.H50Q, a novel pathogenic mutation for Parkinson's disease. Mov. Disord. 28, 811-813. doi: 10.1002/mds.25421

Barria, M. A., Gonzalez-Romero, D., and Soto, C. (2012). Cyclic amplification of prion protein misfolding. Methods Mol. Biol. 849, 199-212. doi: 10.1007/978-161779-551-0_14

Bendor, J. T., Logan, T. P., and Edwards, R. H. (2013). The function of alphasynuclein. Neuron 79, 1044-1066. doi: 10.1016/j.neuron.2013.09.004

Bousset, L., Pieri, L., Ruiz-Arlandis, G., Gath, J., Jensen, P. H., Habenstein, B., et al. (2013). Structural and functional characterization of two alpha-synuclein strains. Nat. Commun. 4:2575. doi: 10.1038/ncomms3575

Braak, H., Del Tredici, K., Rub, U., de Vos, R. A., Jansen Steur, E. N., and Braak, E. (2003). Staging of brain pathology related to sporadic Parkinson's disease. Neurobiol. Aging 24, 197-211. doi: 10.1016/s0197-4580(02)00065-9
MINECO (BIO2015-70092-R) and the European Research Council (Contract 648201).

\section{ACKNOWLEDGMENTS}

We thank the Infraestructura Científica y Técnica Singular NMR facility at Centres Científics i Tecnològics de la Universitat de Barcelona for help with NMR, the Servei de Microscòpia at Universitat Autònoma de Barcelona for their help with TEM, and Anna Villar-Pique for help with plasmid construction. The worm strain UA196 used for neurodegeneration assays was a generous gift of Dr. Guy A. Caldwell.

\section{SUPPLEMENTARY MATERIAL}

The Supplementary Material for this article can be found online at: https://www.frontiersin.org/articles/10.3389/fnmol. 2019.00306/full\#supplementary-material

FIGURE S1 $\mid \alpha$-Synuclein soluble fraction at the end of the aggregation. (A) Soluble fraction of $\alpha$-Syn when incubated in absence (black) or presence (green) of ZPD-2 in PBS solution. (B) Soluble fraction of strains B and C at final point of the aggregation when incubated in presence (green) or absence (black) of ZPD-2.

FIGURE S2 | Lack of interaction between monomeric $\alpha$-synuclein and ZPD-2 assessed by NMR. Superposition of the $1 \mathrm{H}-15 \mathrm{~N} \mathrm{HSQC} \mathrm{NMR} \mathrm{spectra} \mathrm{of}$ $15 \mathrm{~N}$-labeled $\alpha$-Syn $(70 \mu \mathrm{M})$ in absence (black) and presence (green) of $100 \mu \mathrm{M}$ of ZPD-2.

FIGURE S3 | PMCA assay at early stages. Tricine-SDS-PAGE gels of untreated (middle) and ZPD-2-treated (right) PMCA samples before (-) and after (+) being digested with proteinase K. Soluble $\alpha$-Syn and PMCA steps 1-3 are shown.

FIGURE S4 | Toxicity assays. Analysis of neuronal cells culture survival in presence of different concentration of ZPD-2. Survival is potted as normalized means. Error bars are shown as standard error of means values, where $p<0.001$ was indicated by ***.

FIGURE S5 | C. elegans lifespan analysis. Effect of ZPD-2 treatment (green) on the survival of PD model animals, in comparison with untreated PD worms (black). The data represent the survival ratio (approximately 60-80 animals per group).

FIGURE S6 | Distribution of functional neurons in the C. elegans dopaminergic model. Normal distribution of the remaining functional dopaminergic (DA) neurons in transgenic animals when treated with ZPD-2 (green) or vehicle (gray). The dashed line delimits animals having four or more functional DA neurons.
Brenner, S. (1974). The genetics of Caenorhabditis elegans. Genetics 77, 71-94. Bulawa, C. E., Connelly, S., Devit, M., Wang, L., Weigel, C., Fleming, J. A., et al. (2012). Tafamidis, a potent and selective transthyretin kinetic stabilizer that inhibits the amyloid cascade. Proc. Natl. Acad. Sci. U.S.A. 109, 9629-9634. doi: 10.1073/pnas.1121005109

Cao, S., Gelwix, C. C., Caldwell, K. A., and Caldwell, G. A. (2005). Torsin-mediated protection from cellular stress in the dopaminergic neurons of Caenorhabditis elegans. J. Neurosci. 25, 3801-3812. doi: 10.1523/jneurosci.5157-04.2005

Carija, A., Pinheiro, F., Pujols, J., Bras, I. C., Lazaro, D. F., Santambrogio, C., et al. (2019). Biasing the native alpha-synuclein conformational ensemble towards compact states abolishes aggregation and neurotoxicity. Redox Biol. 22:101135. doi: 10.1016/j.redox.2019.101135

Crespo, R., Villar-Alvarez, E., Taboada, P., Rocha, F. A., Damas, A. M., and Martins, P. M. (2016). What can the kinetics of amyloid fibril formation tell about offpathway aggregation? J. Biol. Chem. 291, 2018-2032. doi: 10.1074/jbc.M115. 699348 
Dehay, B., Bourdenx, M., Gorry, P., Przedborski, S., Vila, M., Hunot, S., et al. (2015). Targeting alpha-synuclein for treatment of Parkinson's disease: mechanistic and therapeutic considerations. Lancet. Neurol. 14, 855-866. doi: 10.1016/S1474-4422(15)00006-X

Dexter, D. T., and Jenner, P. (2013). Parkinson disease: from pathology to molecular disease mechanisms. Free Radic. Biol. Med. 62, 132-144. doi: 10. 1016/j.freeradbiomed.2013.01.018

Gao, J., Perera, G., Bhadbhade, M., Halliday, G. M., and Dzamko, N. (2019). Autophagy activation promotes clearance of alpha-synuclein inclusions in fibril-seeded human neural cells. J. Biol. Chem. 294, 14241-14256. doi: 10.1074/ jbc.RA119.008733

Hamamichi, S., Rivas, R. N., Knight, A. L., Cao, S., Caldwell, K. A., and Caldwell, G. A. (2008). Hypothesis-based RNAi screening identifies neuroprotective genes in a Parkinson's disease model. Proc. Natl. Acad. Sci. U.S.A. 105, 728-733. doi: 10.1073/pnas.0711018105

Hansen, C., Angot, E., Bergstrom, A. L., Steiner, J. A., Pieri, L., Paul, G., et al. (2011). alpha-Synuclein propagates from mouse brain to grafted dopaminergic neurons and seeds aggregation in cultured human cells. J. Clin. Invest. 121, 715-725. doi: 10.1172/JCI43366

Harrington, A. J., Yacoubian, T. A., Slone, S. R., Caldwell, K. A., and Caldwell, G. A. (2012). Functional analysis of VPS41-mediated neuroprotection in Caenorhabditis elegans and mammalian models of Parkinson's disease. J. Neurosci. 32, 2142-2153. doi: 10.1523/jneurosci.2606-11.2012

Hauser, R. A. (2015). alpha-Synuclein in Parkinson's disease: getting to the core of the matter. Lancet. Neurol. 14, 785-786. doi: 10.1016/s1474-4422(15)00136-2

Herva, M. E., Zibaee, S., Fraser, G., Barker, R. A., Goedert, M., and Spillantini, M. G. (2014). Anti-amyloid compounds inhibit alpha-synuclein aggregation induced by protein misfolding cyclic amplification (PMCA). J. Biol. Chem. 289, 11897-11905. doi: 10.1074/jbc.M113.542340

Ibanez, P., Bonnet, A. M., Debarges, B., Lohmann, E., Tison, F., Pollak, P., et al. (2004). Causal relation between alpha-synuclein gene duplication and familial Parkinson's disease. Lancet 364, 1169-1171. doi: 10.1016/s0140-6736(04) 17104-3

Kim, H., Calatayud, C., Guha, S., Fernandez-Carasa, I., Berkowitz, L., CarballoCarbajal, I., et al. (2018). The small GTPase RAC1/CED-10 is essential in maintaining dopaminergic neuron function and survival against alphasynuclein-induced toxicity. Mol. Neurobiol. 55, 7533-7552. doi: 10.1007/ s12035-018-0881-7

Kruger, R., Kuhn, W., Muller, T., Woitalla, D., Graeber, M., Kosel, S., et al. (1998). Ala30Pro mutation in the gene encoding alpha-synuclein in Parkinson's disease. Nat. Genet. 18, 106-108.

Levin, J., Schmidt, F., Boehm, C., Prix, C., Botzel, K., Ryazanov, S., et al. (2014). The oligomer modulator anle138b inhibits disease progression in a Parkinson mouse model even with treatment started after disease onset. Acta Neuropathol. 127, 779-780. doi: 10.1007/s00401-014-1265-3

Li, B., Ge, P., Murray, K. A., Sheth, P., Zhang, M., Nair, G., et al. (2018). Cryo-EM of full-length alpha-synuclein reveals fibril polymorphs with a common structural kernel. Nat. Commun. 9:3609. doi: 10.1038/s41467-018-05971-2

Marti, M. J., Tolosa, E., and Campdelacreu, J. (2003). Clinical overview of the synucleinopathies. Mov. Disord. 18(Suppl. 6), S21-S27.

Marvian, A. T., Koss, D. J., Aliakbari, F., Morshedi, D., and Outeiro, T. F. (2019). In vitro models of synucleinopathies: informing on molecular mechanisms and protective strategies. J. Neurochem. 150, 535-565. doi: 10.1111/jnc.14707

McCormack, A. L., Mak, S. K., Henderson, J. M., Bumcrot, D., Farrer, M. J., and Di Monte, D. A. (2010). Alpha-synuclein suppression by targeted small interfering RNA in the primate substantia nigra. PLoS One 5:e12122. doi: 10.1371/journal. pone.0012122

Morales, R., Duran-Aniotz, C., Diaz-Espinoza, R., Camacho, M. V., and Soto, C. (2012). Protein misfolding cyclic amplification of infectious prions. Nat. Protoc. 7, 1397-1409. doi: 10.1038/nprot.2012.067

Moree, B., Yin, G., Lazaro, D. F., Munari, F., Strohaker, T., Giller, K., et al. (2015). Small molecules detected by second-harmonic generation modulate the conformation of monomeric alpha-synuclein and reduce its aggregation in cells. J. Biol. Chem. 290, 27582-27593. doi: 10.1074/jbc.M114.636027

Munoz-Lobato, F., Rodriguez-Palero, M. J., Naranjo-Galindo, F. J., Shephard, F., Gaffney, C. J., Szewczyk, N. J., et al. (2014). Protective role of DNJ-27/ERdj5 in Caenorhabditis elegans models of human neurodegenerative diseases. Antioxid. Redox Signal. 20, 217-235. doi: 10.1089/ars.2012.5051

Nussbaum, R. L., and Ellis, C. E. (2003). Alzheimer's disease and Parkinson's disease. N. Engl. J. Med. 348, 1356-1364.
Peelaerts, W., Bousset, L., Van der Perren, A., Moskalyuk, A., Pulizzi, R., Giugliano, M., et al. (2015). alpha-Synuclein strains cause distinct synucleinopathies after local and systemic administration. Nature 522, 340-344. doi: 10.1038/ nature 14547

Perni, M., Galvagnion, C., Maltsev, A., Meisl, G., Muller, M. B., Challa, P. K., et al. (2017). A natural product inhibits the initiation of alpha-synuclein aggregation and suppresses its toxicity. Proc. Natl. Acad. Sci. U.S.A. 114, E1009-E1017.

Polymeropoulos, M. H., Lavedan, C., Leroy, E., Ide, S. E., Dehejia, A., Dutra, A., et al. (1997). Mutation in the alpha-synuclein gene identified in families with Parkinson's disease. Science 276, 2045-2047. doi: 10.1126/science.276.5321. 2045

Pujols, J., Pena-Diaz, S., Conde-Gimenez, M., Pinheiro, F., Navarro, S., Sancho, J., et al. (2017). High-throughput screening methodology to identify alphasynuclein aggregation inhibitors. Int. J. Mol. Sci. 18:E478. doi: 10.3390/ ijms 18030478

Pujols, J., Pena-Diaz, S., Lazaro, D. F., Peccati, F., Pinheiro, F., Gonzalez, D., et al. (2018). Small molecule inhibits alpha-synuclein aggregation, disrupts amyloid fibrils, and prevents degeneration of dopaminergic neurons. Proc. Natl. Acad. Sci. U.S.A. 115, 10481-10486. doi: 10.1073/pnas.1804198115

Sabate, R., Gallardo, M., and Estelrich, J. (2003). An autocatalytic reaction as a model for the kinetics of the aggregation of beta-amyloid. Biopolymers 71, 190-195. doi: 10.1002/bip.10441

Sant'Anna, R., Gallego, P., Robinson, L. Z., Pereira-Henriques, A., Ferreira, N., Pinheiro, F., et al. (2016). Repositioning tolcapone as a potent inhibitor of transthyretin amyloidogenesis and associated cellular toxicity. Nat. Commun. 7:10787. doi: 10.1038/ncomms10787

Serpell, L. C., Berriman, J., Jakes, R., Goedert, M., and Crowther, R. A. (2000). Fiber diffraction of synthetic alpha-synuclein filaments shows amyloid-like cross-beta conformation. Proc. Natl. Acad. Sci. U.S.A. 97, 4897-4902. doi: 10.1073/pnas. 97.9.4897

Silva, B., Einarsdóttir, O., Fink, and Uversky, V. (2011). Modulating $\alpha$-synuclein misfolding and fibrillation in vitro by agrochemicals. Res. Rep. Biol. 2, 43-56.

Singleton, A. B., Farrer, M., Johnson, J., Singleton, A., Hague, S., Kachergus, J., et al. (2003). alpha-Synuclein locus triplication causes Parkinson's disease. Science 302:841. doi: 10.1126/science. 1090278

Spillantini, M. G., Crowther, R. A., Jakes, R., Cairns, N. J., Lantos, P. L., and Goedert, M. (1998). Filamentous alpha-synuclein inclusions link multiple system atrophy with Parkinson's disease and dementia with Lewy bodies. Neurosci. Lett. 251, 205-208. doi: 10.1016/s0304-3940(98)00 504-7

Spillantini, M. G., Schmidt, M. L., Lee, V. M., Trojanowski, J. Q., Jakes, R., and Goedert, M. (1997). Alpha-synuclein in lewy bodies. Nature 388, 839-840.

Sulston, J., Dew, M., and Brenner, S. (1975). Dopaminergic neurons in the nematode Caenorhabditis elegans. J. Comp. Neurol. 163, 215-226.

Tatenhorst, L., Eckermann, K., Dambeck, V., Fonseca-Ornelas, L., Walle, H., Lopes da Fonseca, T., et al. (2016). Fasudil attenuates aggregation of alpha-synuclein in models of Parkinson's disease. Acta Neuropathol. Commun. 4:39. doi: 10.1186/ s40478-016-0310-y

van Ham, T. J., Thijssen, K. L., Breitling, R., Hofstra, R. M., Plasterk, R. H., and Nollen, C. (2008). elegans model identifies genetic modifiers of alphasynuclein inclusion formation during aging. PLoS Genet. 4:e1000027. doi: 10. 1371/journal.pgen.1000027

Winner, B., Jappelli, R., Maji, S. K., Desplats, P. A., Boyer, L., Aigner, S., et al. (2011). In vivo demonstration that alpha-synuclein oligomers are toxic. Proc. Natl. Acad. Sci. U.S.A. 108, 4194-4199. doi: 10.1073/pnas.1100976108

Xue, W. F., Hellewell, A. L., Hewitt, E. W., and Radford, S. E. (2010). Fibril fragmentation in amyloid assembly and cytotoxicity: when size matters. Prion 4, 20-25. doi: 10.4161/pri.4.1.11378

Conflict of Interest: The authors declare that the research was conducted in the absence of any commercial or financial relationships that could be construed as a potential conflict of interest.

Copyright (c) 2019 Peña-Díaz, Pujols, Conde-Giménez, Čarija, Dalfo, García, Navarro, Pinheiro, Santos, Salvatella, Sancho and Ventura. This is an open-access article distributed under the terms of the Creative Commons Attribution License (CC BY). The use, distribution or reproduction in other forums is permitted, provided the original author(s) and the copyright owner(s) are credited and that the original publication in this journal is cited, in accordance with accepted academic practice. No use, distribution or reproduction is permitted which does not comply with these terms. 